RICARDO NICOTRA

\title{
ONLINE PROFILING
}

A proteção dos dados pessoais no processo de geração de perfil digital

Dissertação de Mestrado

Orientadora: Professora Associada Dra. Cíntia Rosa Pereira de Lima.

UNIVERSIDADE DE SÃO PAULO

FACULDADE DE DIREITO

São Paulo - SP

2018 

RICARDO NICOTRA

\section{ONLINE PROFILING}

A proteção dos dados pessoais no processo de geração de perfil digital

Dissertação apresentada à Banca Examinadora do Programa de Pós-Graduação em Direito, da Faculdade de Direito da Universidade de São Paulo, como exigência parcial para a obtenção do título de Mestre em Direito, na área de concentração de Direito Civil, sob a orientação da Professora Associada Dra. Cíntia Rosa Pereira de Lima.

UNIVERSIDADE DE SÃO PAULO

FACULDADE DE DIREITO

São Paulo - SP 
Nicotra, Ricardo

Online Profiling - A proteção dos dados pessoais no processo de geração do perfil digital / Ricardo Nicotra. - São Paulo / SP, 2018. 160 f.

Orientadora: Profa. Associada Dra. Cíntia Rosa Pereira de Lima.

Dissertação (Mestrado em Direito Civil) - Faculdade de Direito da Universidade de São Paulo, 2018.

1. Online Profiling. 2. Privacidade. 3. Big Data. 
RICARDO NICOTRA

\section{ONLINE PROFILING}

A proteção dos dados pessoais no processo de geração de perfil digital

Dissertação apresentada à Faculdade de Direito da Universidade de São Paulo, sob a orientação da Professora Associada Dra. Cíntia Rosa Pereira de Lima, como requisito parcial para a obtenção do título de Mestre, na área de Direito Civil.

Aprovado em:

Banca Examinadora:

Prof:: Instituição:

Julgamento: Assinatura:

Prof.: Instituição:

Julgamento: Assinatura:

Prof.: Instituição:

Julgamento: Assinatura: 

Aos meus pais, João e Maria Nicotra, pela vida que me deram.

À minha esposa Andréia pela vida que me dá.

À minha filha Sophia que dá sentido à minha vida.

Ao Único Deus Criador e ao Seu Filho Jesus Cristo pela vida ontem, hoje e sempre.

"Além disso, meu filho, fique atento: fazer livros é um trabalho sem fim, e muito estudo cansa o corpo. Fim do discurso. Tudo foi ouvido. Teme a Deus e observa seus mandamentos, porque este é o dever de todo o homem. Porque Deus julgará toda obra, até mesmo a que está escondida, para ver se é boa ou má." - Sábio Salomão - Eclesiastes 12:12-14 - Versão da Bíblia de Jerusalém. 



\section{RESUMO}

NICOTRA, Ricardo. Online profiling.A proteção dos dados pessoais no processo de geração de perfil digital. 2018. 160f. Dissertação (Mestrado) - Faculdade de Direito da Universidade de São Paulo. São Paulo, 2018.

O desenvolvimento da tecnologia digital trouxe inúmeros benefícios aos indivíduos, empresas e governos. Aplicativos gratuitos desenvolvidos por grandes empresas privadas permitem fazer buscas na internet, conectar-se com seus amigos, fazer compras online, encontrar uma pessoa interessante para relacionamento, assistir vídeos com temas do seu interesse e fazer você chegar mais rapidamente a um lugar que nunca foi antes.

Ao utilizar cada um destes aplicativos o usuário fornece a estas empresas seus dados pessoais, o que inclui dados de comportamento, preferências, posição geografia e deslocamento físico, dentre outros. Estes dados são capturados, armazenados, agregados, analisados, criando-se, desta forma, um perfil online do usuário da internet. Este perfil é compartilhado com empresas terceirizadas e utilizado para diversas finalidades, das quais a mais propalada é a aparentemente inofensiva veiculação de publicidade adequada ao perfil.

Este processo multifásico, denominado de "online profiling", que vai desde a coleta até a utilização dos dados gera diversos riscos aos usuários de internet os quais podem ter sua privacidade violada, sendo discriminados e estigmatizados, muitas vezes em decorrência de uma decisão automatizada.

Não há dúvidas de que este novo fato social merece atenção do ponto de vista jurídico. O Direito, principalmente no Brasil, tem caminhado de forma mais lenta do que a tecnologia, claudicando em sua tarefa de regular este relevante fato social de modo a minimizar os riscos dos indivíduos. 
Após uma análise do direito à privacidade em sua multiplicidade de aspectos, este trabalho tratará das iniciativas legislativas de proteção de dados pessoais e dos princípios subjacentes. Fará uma crítica a paradigmas e modelos de proteção que se baseiam em conceitos questionáveis como dados anônimos, dados sensíveis e consentimento informado.

O modelo de proteção estadounidense bem como o europeu, incluindo o novo Regulamento (GDPR), serão discutidos principalmente em seus aspectos que dizem respeito à prática do "online profiling". Os projetos de lei em tramitação no Congresso Nacional brasileiro também são objeto deste estudo. No entanto, a presente monografia não se limita a discutir a legislação como única forma de resolver o problema da proteção dos dados pessoais no âmbito do "online profile". É também feita uma análise sobre modos complementares de proteção como a autorregulação do setor e a instituição de um órgão independente de proteção de dados.

A presente dissertação, além de discutir possíveis soluções, aponta para tendências como a que coloca a ênfase da proteção não na fase de coleta dos dados, mas na sua utilização, opção que se justifica pela possibilidade de proveito social na boa utilização desta gigantesca massa de dados pessoais.

Palavras Chaves: proteção de dados pessoais - online profiling - perfil digital, big data - privacidade - direitos da personalidade 


\begin{abstract}
NICOTRA, Ricardo. Online profiling. Personal Data Protection in the online profiling process. 2017. 160f. Thesis (Master) - Faculty of Law of the University of São Paulo. São Paulo, 2017.
\end{abstract}

The development of digital technology has brought many benefits to people, companies, and governments. Free apps developed by big private companies allow users to search on internet, connect with friends, shop online, met someone special, watch videos online, get the best route for a unvisited place.

The user sends personal data to those companies every time he uses those applications. That includes behaviour data, preferences, tracking location and others. Those data are captured, stored, aggregated, analysed, building up a user online profile. This profile is shared with third party companies and used to several goals, among which the most publicized is the online advertising.

This multiphase process, the so-called online profiling, going from the data tracking and collection until the use of the data creates several types of risk to internet users. These users may have their privacy violated, being discriminated or stigmatized, many times by an automated decision.

The emergence of this new social fact deserves attention from a juridical viewpoint. The Law, mainly in Brazil, has evolved tardier than technology, hobbling in its duty of regulating this important social fact to diminish the individual risks.

After analysing the right of privacy in its broad range of aspects, this paper will mention the data protection initiatives, laws, and principles. A review of paradigms and models of data protection will be made discussing concepts such as anonymization, sensitive data, and informed consent. 
The paper will discuss the data protection model adopted in United States and in Europe, including the new Regulation (GDPR), mainly in the aspects related to the online profiling. The data protection bills under discussion in the Brazilian Parliament are also object of analysis. However, in this monography the law is not the only technique to solve the issue of data protection created by the online profiling. An analysis of additional ways to protect the individuals such as selfregulation in the industry and the establishment of a data protection independent supervisory authority.

This paper not only discuss possible ways to address the problem but also points out trends in the data protection such as the proposal to focus not the data capture regulation but solely its use, considering the possibility of social gains from a good use of this massive amount of personal data.

Keywords: personal data protection - online profiling - big data - privacy personality rights. 


\section{LISTA DE ABREVIATURAS}

CC - Código Civil

CDC - Código de Defesa do Consumidor

CONAR - Conselho Nacional de Autorregulamentação Publicitária

CPF - Cadastro de Pessoas Físicas

DNT - Do Not Track

DPA - Data Protection Authority

FTC - Federal Trade Commission

GDPR - General Data Protection Regulation

HIPAA - Health Insurance Portability and Accountability Act

HTTP - Hyper Text Transfer Protocol

HTTPS - Hyper Text Transfer Protocol Secure

IAB - INTERACTIVE ADVERTISING BUREAU

IP - Internet Protocol

LSO - Local Shared Objects

$\mathrm{MCl}$ - Marco Civil da Internet

NAI - Network Advertising Initiative

NHS - National Health Service

OECD - Organisation for Economic Co-operation and Development

PCAST - President's Council of Advisors on Science and Technology

PII - Personally Identifiable Information 
$\mathrm{PL}$ - Projeto de Lei

SNS - Social Networking Site

STF - Supremo Tribunal Federal

STJ - Superior Tribunal de Justiça

URL - Uniform Resource Locator

W3C - World Wide Web Consortium 


\section{LISTA DE FIGURAS}

Figura 1 - Evolução das Receitas (Publicidade Online X TV) …………..............47

Figura 2 - Internet Explorer: Opções permissivas para Cookies de Terceiros ......58

Figura 3 - Opção de Cookies padrão permissiva no Chrome................................59

Figura 4 - Mozilla Firefox: Opções permissivas para "cookies de fora" (terceiros) 59

Figura 5 - Botão Like no Site de Bibliotecas da USP ...........................................61

Figura 6 - Site de Bibliotecas da USP Conecta com Facebook ...........................62

Figura 7 - Ícone do Facebook na Página Sobre Câncer do NHS...........................64

Figura 8 - Alterações e Tendências nas Tecnologias de Rastreamento entre 2012

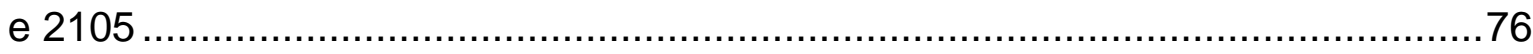





\section{SUMÁRIO}

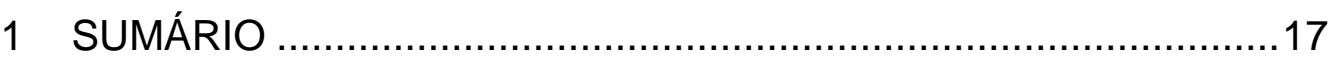

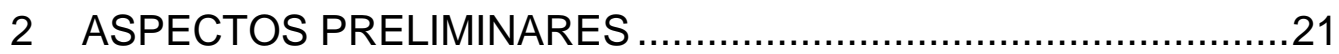

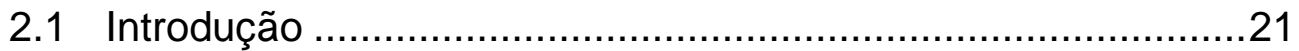

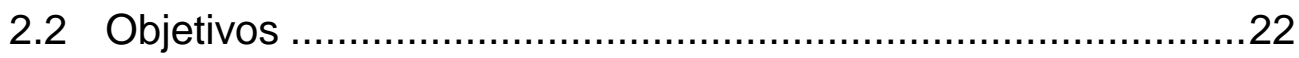

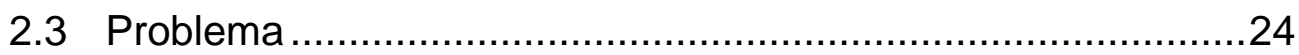

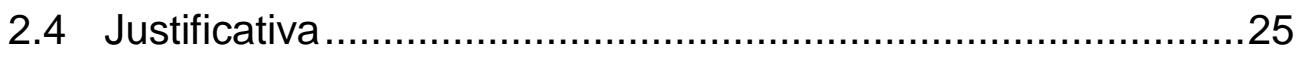

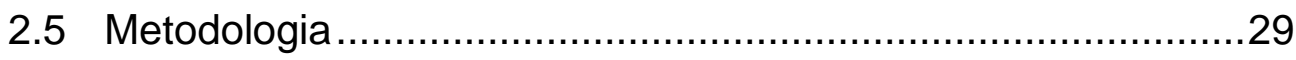

2.6 Termos e Definições.............................................................

2.6.1 Online Profiling...............................................................

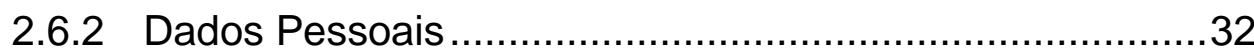

2.6.3 Sujeitos Relacionados aos Dados .....................................36

2.7 Classificação dos Dados Pessoais..........................................37

3 O ONLINE PROFILING: A GERAÇÃO DE PERFIL DIGITAL .........43

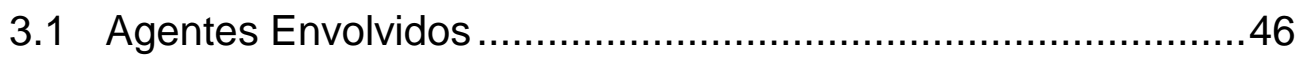

3.1.1 Empresas de Publicidade Online ………...........................46

3.1.2 Data Brokers ............................................................. 48

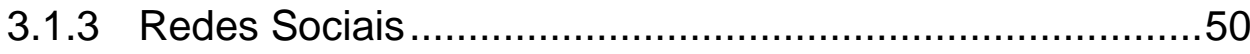

3.1.4 Provedores de Conteúdo ……………………................50

3.2 A Captura e Rastreamento dos Dados Pessoais .....................51

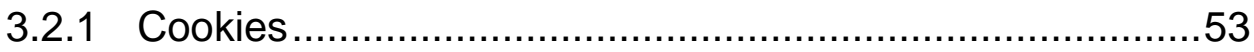

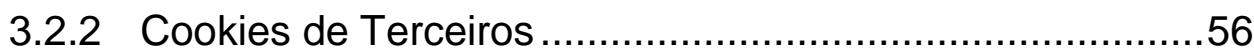

3.2.3 Rastreamento por Redes Sociais (Facebook) ...................60

3.2.4 Privacidade em Sites para Adultos ………….....................65

3.2.5 A Política de Não Rastreamento ("Do Not Track")..............68

3.2.6 Flash Cookies ................................................................ 
3.2.7 HTML5. 74

3.3 O Armazenamento dos Dados Pessoais (Big Data) ..............77

3.4 O Processamento dos Dados Pessoais ..............................79

3.5 A Utilização dos Dados Pessoais...................................... 81

3.6 O Compartilhamento dos Dados Pessoais .......................... 83

4 IMPACTOS DO ONLINE PROFILING ............................... 87

4.1 Riscos de Dano no Uso Indevido dos Dados ........................87

4.2 Críticas ao Paradigma da Proteção Via Anonimização ............ 88

5 A PROTEÇÃO DA PRIVACIDADE INFORMACIONAL ................97

5.1 A Privacidade e a Proteção dos Dados Pessoais ................... 97

5.2 A Titularidade dos Dados Pessoais .................................. 102

5.3 A Privacidade Informacional Como Direito da Personalidade 104

6 PRIVACIDADE INFORMACIONAL - FORMAS DE PROTEÇÃO 107

6.1 Regulação Pelo Livre Mercado .................................... 107

6.1.1 A Ineficácia do Modelo de Consentimento Informado ..... 109

6.1.2 A Impossibilidade de Enforcement ......................... 115

6.2 Autorregulação..................................................... 116

6.3 Órgãos de Regulação e Controle .....................................119

7 A Tutela Jurídica no Exterior e no Brasil ............................... 123

7.1 A Tutela Jurídica dos Dados Pessoais nos Estados Unidos .. 123

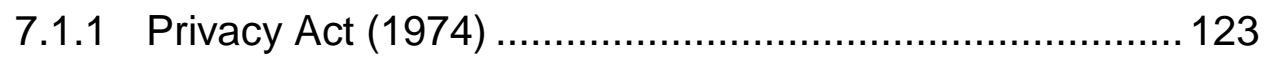

7.1 .2 PCAST Report.................................................. 126

7.2 A Proteção de Dados Pessoais na Comunidade Europeia .... 128

7.2.1 A Diretiva 95/46, Regulamento 2016/679 e o Profiling .... 132

7.3 A Tutela Jurídica dos Dados Pessoais no Brasil................. 140

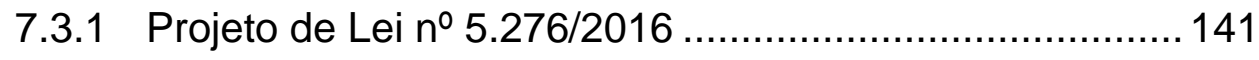


8 O Modelo da Matriz de Risco 145

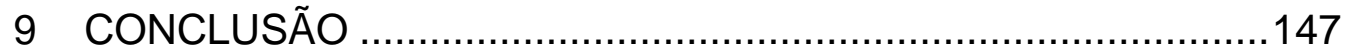

10 ANEXO I: EXEMPLOS DE DESANONIMIZAÇÃO.....................149

10.1 Pesquisas do Motor de Buscas da America Online (AOL) ...149

10.2 Massachusetts Group Insurance Commission (GIC)............150

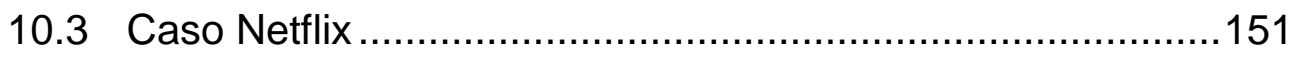

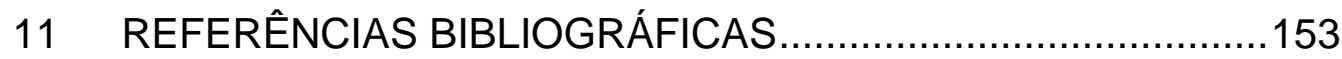

11.1 LIVROS E MONOGRAFIAS ……………....................153

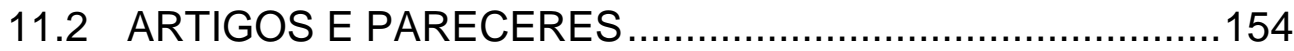

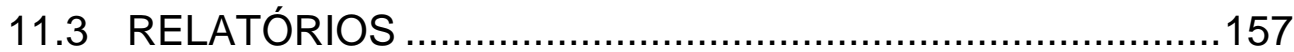

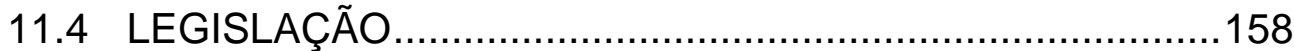

11.5 WEBSITES 



\section{ASPECTOS PRELIMINARES}

\subsection{Introdução}

O objeto de estudo desta dissertação é a tutela da privacidade dos dados pessoais em face do processo de geração de perfil digital dos usuários da internet, prática mais conhecida na literatura especializada como "online profiling"1. Este processo consiste na captura, processamento, utilização e compartilhamento dos dados pessoais, estando nestes incluídos os dados de comportamento online de usuários da internet rastreados e coletados por aquelas que denominamos, de forma genérica neste trabalho, de "empresas de internet"2. Os dados obtidos por estas empresas são armazenados inicialmente de forma bruta em bases de dados que, posteriormente, são submetidas a um processamento cujo objetivo é compor o perfil do usuário (profiling). Este perfil pode ser usado para diversas finalidades, sendo a veiculação de publicidade personalizada a finalidade mais propalada. ${ }^{3}$

Inicialmente será descrito o processo de online profiling, o que incluirá desde as tecnologias de captura de dados por rastreamento até, finalmente, a utilização e eventual compartilhamento de dados entre as empresas de internet. Discorrer-se-á sobre os impactos do online profiling na esfera jurídica dos usuários de internet com ênfase nos riscos decorrentes de decisões automatizadas que

${ }^{1}$ A expressão "online profiling" remete ao ato de compor, construir, elaborar o perfil digital de um usuário de internet, ou seja, em sentido estrito "online profiling" significa apenas a elaboração do perfil do usuário. No entanto, admite-se, neste trabalho, o significado em sentido amplo da expressão que remete ao processo que vai desde a obtenção dos dados, por captura ou rastreamento, até seu destino que pode ser a utilização ou o compartilhamento com terceiros das informações obtidas e processadas.

2 Os agentes que protagonizam o processo de online profiling são designados neste trabalho de forma genérica como "empresas de internet". Na seção apropriada para a explicação dos termos comuns desta dissertação, as espécies deste gênero serão apresentadas e o papel de cada uma delas será detalhado.

3 O Facebook, em seus termos e políticas de uso, informa que "Usamos as informações que temos para melhorar nossos sistemas de publicidade e medição; assim, podemos mostrar anúncios relevantes a você dentro e fora dos nossos Serviços, além de medir a eficácia e o alcance dos anúncios e serviços." - Disponível em: <https://www.facebook.com/about/privacy>. Acesso em: 17.nov.2017. A Google, na mesma linha, informa que "usamos essas informações para oferecer ao usuário um conteúdo específico, por exemplo, fornecer resultados mais relevantes de pesquisa e anúncios.". Disponivel em: <https://www.google.com.br/intl/pt-BR/policies/privacy/?fg=1\#infouse>. Acesso em: 17.nov.2017. 
geram discriminação e estigmatização dos sujeitos relacionados aos dados pessoais. Demonstrar-se-á o agravamento da vulnerabilidade do usuário e do risco de violação de sua privacidade em face da possibilidade real de diversas empresas de internet, em regime de parceria, compartilharem os dados pessoais, compartilhamento que permite a agregação de uma quantidade maior de dados possibilitando a geração de um perfil (profiling) mais preciso, detalhado e revelador não apenas sobre as características pessoais do sujeito relacionado aos dados, mas também sobre suas preferências e tendências. Apontar-se-á, por fim, o aumento da probabilidade de desanonimização de dados em decorrência do amplo compartilhamento dos dados pessoais entre as empresas de internet e do constante incremento informacional do famigerado Big Data.

A partir deste ponto, tendo já alcançado uma visão satisfatória do processo objeto de análise e da forma como ele coloca o usuário numa situação de vulnerabilidade, num segundo momento será abordado o tratamento jurídico conferido aos dados pessoais com ênfase na tutela jurídica do sujeito relacionado aos dados. Serão analisadas de forma crítica as normas jurídicas em vigor e as projetadas que regulam a proteção de dados pessoais no Brasil e no exterior, normas geralmente fundamentadas no princípio do consentimento informado e na crença da possibilidade de anonimização de dados.

A crítica da norma e de suas premissas será apresentada levando-se em conta os valores e princípios que justificam a proteção dos dados pessoais bem como a realidade fática e técnica do contexto do online profiling, em especial a forma como o consentimento para a coleta, tratamento, utilização e compartilhamento de dados tem sido obtido do sujeito relacionado aos dados.

Finalmente, algumas propostas de controle serão apresentadas objetivando-se tutelar de forma mais eficaz os direitos dos sujeitos relacionados aos dados de comportamento online e dados derivados do processo de profiling.

\subsection{Objetivos}

O objetivo geral da pesquisa é a apresentação do recente fato social denominado online profiling bem como a análise dos direitos do usuário da internet 
sobre a captura, processamento e utilização dos seus dados pessoais, incluindo os dados sobre seus hábitos de navegação e dados derivados de processamento ou tratamento. Estes direitos serão analisados em face das práticas difundidas entre empresas de internet, práticas que envolvem a coleta dos referidos dados, muitas vezes sem informar de forma satisfatória ou receber o consentimento livre, específico e inequívoco do usuário.

Como objetivos específicos do estudo, elenca-se, de forma sucinta, os seguintes:

- Apresentar, de forma sucinta, algumas tecnologias utilizadas para a captura e tratamento de dados pessoais e discutir a adequação da cada uma delas em face do ordenamento jurídico vigente e projetado.

- Compreender como a evolução tecnológica é capaz de atribuir novos aspectos de interesse aos direitos clássicos como o direito à privacidade e intimidade.

- Analisar as dimensões do direito à privacidade, principalmente aquela envolvendo a proteção dos dados pessoais e os dados de comportamento e histórico de navegação na internet.

- Verificar quais dados, de fato, são coletados por empresas de internet e qual o nível de informação oferecido ao usuário antes da coleta bem como o grau de consentimento exigido para que a coleta, processamento, utilização e compartilhamento sejam realizados.

- Qualificar a natureza jurídica da conduta das empresas de internet que coletam estes dados tendo como base o ordenamento jurídico pátrio, em especial os princípios que tutelam o direito do consumidor e que estão na base principiológica dos projetos de lei que versam sobre proteção de dados pessoais.

- Discutir sobre as formas utilizadas para proteger o usuário da internet das práticas abusivas de uso de dados pessoais e de dados de navegação tendo 
como subsídio a análise da jurisprudência e legislação estrangeiras, principalmente aquela vigente na União Europeia.

- Propor modelos de governança a serem observados pelas empresas de internet, objetivando-se a adequação das necessidades de mercado com a proteção dos direitos de personalidade dos usuários da internet.

\subsection{Problema}

A presente dissertação se propõe a analisar as seguintes questões:

Qual a extensão do direito fundamental à privacidade e intimidade? Este direito inclui a proteção dos dados pessoais coletados na internet e dados de navegação que refletem o comportamento, preferências e interesses do usuário, ainda que o sujeito relacionado aos dados não esteja inequivocamente identificado?

A proteção de dados pessoais pode ser estendida aos dados pessoais públicos como, por exemplo, estado civil e data de nascimento? Deve a proteção ser estendida aos dados derivados, entendidos como aqueles que resultam da fase de análise dos dados coletados?

O direito sobre dados pessoais inclui o direito de navegar na internet de forma anônima? Quais são as limitações funcionais razoavelmente esperadas por um usuário que decida navegar na internet de forma anônima?

Qual é o nível de informação a ser disponibilizada e consentimento a ser obtido do usuário para que as empresas de internet possam: (a) capturar dados pessoais e de navegação, (b) submeter estes dados a análises estatísticas e algoritmos para projeções e tendências (e.g. agregação e mineração de dados), (c) utilizar os dados coletados e os dados resultantes das análises para diversas finalidades, incluindo o direcionamento de publicidade, (d) compartilhar estes dados com terceiros, (e) com base nos dados derivados tomarem decisões de forma automatizada que tenham impacto na esfera jurídica do sujeito relacionado aos dados? 
O ordenamento jurídico brasileiro (incluindo os projetos de lei de proteção de dados pessoais) regula de forma satisfatória as práticas objeto deste estudo sendo, portanto, capaz de tutelar de forma preventiva o direito dos usuários da internet no tocante aos dados pessoais e de navegação coletados, processados e compartilhados? É possível aplicar o Código de Defesa do Consumidor (Lei 8.078/90) e o Marco Civil da Internet (Lei 12.965/2014) para regular as práticas de online profiling?

É possível falar em titularidade dos dados pessoais? Quem é o titular dos dados pessoais? Que direitos decorrem da titularidade destes dados? Estes direitos são absolutos ou podem ser mitigados? Em quais circunstâncias se dá a mitigação? Que outros direitos podem colidir com os direitos decorrentes da titularidade sobre os dados pessoais?

A quais riscos jurídicos estão submetidos os sujeitos cujos dados são coletados, processados e compartilhados por empresas de internet?

Que medidas podem ser tomadas para evitar abusos das empresas de internet que praticam o online profiling?

Que alternativas ao direito positivo podem ser implementadas para assegurar os direitos dos sujeitos relacionados aos dados?

\subsection{Justificativa}

O advento e a disseminação da tecnologia digital e das telecomunicações vêm causando uma verdadeira revolução nas relações humanas. As relações sociais, comerciais e jurídicas foram profundamente afetadas nas últimas décadas com a difusão das ferramentas que usam a internet como plataforma operacional. Este novo cenário impele o jurista à reflexão sobre os novos direitos que emergem desta nova realidade - direitos que, na verdade, podem ser considerados releituras ou novas dimensões de direitos já existentes.

A privacidade é um dos direitos que ganhou nova roupagem na sociedade digital. Da ideia de "o direito de ser deixado só" à proteção dos dados 
pessoais, a mudança de feição deste direito da personalidade decorreu, em grande medida, da evolução tecnológica.

LoUis BRANDeis e Samuel WarRen, em 1890, já haviam notado como o desenvolvimento tecnológico colocaria a privacidade numa posição de vulnerabilidade. À época escreveram o seguinte no clássico artigo "The Right to Privacy":

Recent inventions and business methods call attention to the next step which must be taken for the protection of the person, and for securing to the individual what Judge Cooley calls the right "to be let alone". Instantaneous photographs and newspaper enterprise have invaded the sacred precincts of private and domestic life; and numerous mechanical devices threaten to make good the prediction that "what is whispered in the closet shall be proclaimed from the house-tops. "4

BRANDEIS e WARREN mencionam as "fotografias instantâneas" e seu meio de publicação, os jornais, bem como "numerosos dispositivos mecânicos" como elementos, fruto da evolução tecnológica, que ameaçariam a intimidade dos indivíduos. Se ambos tinham razão naquela época, é forçoso admitir que as ameaças se intensificaram hoje, momento em que a maioria dos transeuntes detém uma câmera fotográfica embutida num dispositivo que permite não só a captura de imagens em lugares públicos e privados, mas sua imediata publicação num espaço digital que pode ser acessado gratuitamente por qualquer pessoa do mundo que, por sua vez, poderá copiar, armazenar ou compartilhar a fotografia ou qualquer outro conteúdo publicado.

${ }^{4}$ WARREN, Samuel D.; BRANDEIS, Louis D.. The Right to Privacy. 4 HARV.L.REV. 193 1890. Disponível em: <http://faculty.uml.edu/sgallagher/Brandeisprivacy.htm>. Acesso em: 01.dez.2017 
Atualmente é comum observar que algumas publicações são compartilhadas de maneira exponencial sendo acessível à maioria dos usuários de internet que utilizam redes sociais ou aplicativos de comunicação instantânea. ${ }^{5}$

Segundo BRANDEIS e WARREN a resposta eficaz para esta crescente capacidade dos governos, da imprensa e das empresas invadirem aspectos até então inacessíveis do indivíduo estaria no direito positivo. Remédios legais deveriam ser desenvolvidos para limitar o acesso destas entidades ao âmbito mais restrito do indivíduo.

O direito positivo, entendido como um conjunto de prescrições destinadas a regularem a conduta humana, tem uma dinâmica própria que, em relação à dinâmica da vida social, é reativa e não proativa. Equivale dizer que as alterações nas condutas sociais se refletem, apenas após algum tempo, no direito posto e não o contrário. É justamente nesta assincronia que está o espaço para o trabalho dos juristas. O vaticínio de BRANDEIS e WARREN se cumpre hoje de uma forma mais intensa do que eles poderiam prever, no entanto o arcabouço legal para a disciplina da matéria ainda é incipiente e insatisfatória e, mesmo quando existente, enfrenta óbices para a efetividade dos direitos e garantias uma vez que as práticas aqui referidas são de difícil fiscalização.

Como se não bastassem as dificuldades já expostas, demonstrar-se-á, ademais, que as pouco numerosas iniciativas legislativas repousam sobre premissas questionáveis, o que levanta dúvidas sobre a eficácia destas medidas protetivas.

As novas práticas perpetradas no espaço digital pelas empresas de internet demandam uma análise aprofundada e um tratamento jurídico adequado.

${ }^{5}$ A este fenômeno de compartilhamento exponencial atribuiu-se a expressão "viralizar" que embora ainda não conste no Vocabulário Ortográfico da Língua Portuguesa (VOLP) da Academia Brasileira de Letras já foi dicionarizado no Houaiss como "verbo - t.d.int. e pron. espalhar(se) como um vírus (p.ex., na internet); tornar-se viral 〈 $v$. uma entrevista nas redes sociais〉 〈processo de afastamento viraliza nas redes) (o boato viralizou-se na internet)" 
A alimentação de bases de dados pessoais e comportamentais com base na navegação do usuário da internet (online behavior) realizada por empresas de internet merecem a especial atenção da sociedade e dos juristas em razão do seguinte:

(a) A coleta e processamento de dados pessoais têm como resultado a geração de informações ${ }^{6}$ que, se publicadas ou utilizadas de forma inadequada, podem violar os direitos e causar danos aos sujeitos relacionados aos dados.

(b) Não é possível afirmar que a coleta e tratamento de dados pessoais e comportamentais realizada atualmente pelas empresas de internet é feita mediante real consentimento dos sujeitos relacionados aos dados. Observa-se, ademais, que o usuário, no momento de eventual autorização para a coleta e utilização de seus dados não recebe informações adequadas e específicas sobre (1) a quantidade e natureza dos dados coletados, (2) o tempo que os dados serão mantidos na base de dados do provedor, (3) o tratamento ao qual serão submetidos os dados, (4) o uso que será feito dos dados, incluindo a possibilidade de cessão ou compartilhamento dos dados com terceiros.

(c) Os dados coletados e as informações geradas a partir de tratamento destes dados têm inequívoco valor econômico porquanto podem gerar ao seu detentor incremento patrimonial em razão da sua utilização (aumento da eficiência de campanhas publicitárias, arbitramento de

6 Dados só se tornam em informação se organizados e analisados adequadamente. Danilo Doneda (2006) diferenciou "dados" de "informações" da seguinte forma: "Em relação à utilização dos termos 'informação' e 'dado', é necessário notar preliminarmente que o conteúdo de ambos os vocábulos se sobrepõe em várias circunstâncias, o que justifica uma certa promiscuidade na sua utilização. Ambos os termos servem para representar um fato, um determinado aspecto de uma realidade. Não obstante, cada um carrega um peso particular a ser levado em conta. Assim, o 'dado' apresenta conotação um pouco mais primitiva e fragmentada, como observamos por exemplo em um autor que o entende como uma informação em estado potencial, antes de ser transmitida; o dado estaria associado a uma espécie de 'pré-informação', anterior à interpretação e ao processo de elaboração. A informação, por sua vez, alude a algo além da representação contida no dado, chegando ao limiar da cognição, e mesmo nos efeitos que esta pode apresentar ao seu receptor" DONEDA, 2006. p. 152. 
preços de produtos e serviços em função do potencial consumidor, cessão ou compartilhamento com terceiros, identificação de risco de crédito de determinados consumidores e quaisquer outras destinações que venham a gerar receitas para o detentor dos referidos dados). Nesta esteira, questiona-se sobre quem é o titular do direito sobre tais dados. Tratando-se de verdadeiras projeções da personalidade de vários indivíduos, não seriam estes os legítimos titulares dos dados e, portanto, merecedores de restituição sobre qualquer resultado economicamente quantificável em decorrência do uso dos dados?

\subsection{Metodologia}

A Ciência do Direito, por pertencer à categoria de Ciências Humanas ou Ciências Sociais, raramente lança mão de processos experimentais cujos resultados servem como "verificações sintéticas" com vistas à comprovação das hipóteses postas à prova.

Como leciona o eminente jurisfilósofo Miguel REALE, "isto não significa que as ciências sociais sejam destituídas de certeza. Esta é obtida mediante o rigor do raciocínio, a objetividade da observação dos fatos sociais e a concordância de seus enunciados"7.

Na visão do memorável Mestre é possível estabelecer leis a partir da observância das mencionadas exigências. Não são leis de causalidade, como na Física ou Química, mas leis de tendência, ou seja, "leis que asseguram certo grau de certeza e previsibilidade". Desta forma, a Ciência do Direito deve observar a lógica e os métodos adequados à sua finalidade.

No estudo do objeto desta dissertação serão utilizados os métodos indutivo e dedutivo. 
Utilizando o método indutivo, partir-se-á da compreensão de fatos particulares para que se chegue a conclusões de ordem geral. Este método será aplicado na parte inicial da dissertação onde o processo de online profiling será apresentado e analisado. As conclusões de ordem geral, resultado da aplicação do método indutivo, devem ter a aptidão para explicar o que há de comum em fatos da mesma natureza. Perceba-se que nesta etapa busca-se melhor compreensão do fato social que é objeto da análise, qual seja, o processo de geração de perfil digital, o online profiling, o que inclui o processo de captura de dados, comumente denominado de online tracking.

Apenas na segunda parte da dissertação, lançar-se-á mão do método dedutivo. Com este método, parte-se de uma verdade sabida, de um fato social tomado em sua generalidade, e aplicando inferências de natureza axiológica, chegar-se-á à conclusão sobre alternativas para o tratamento jurídico do fato social sob análise.

A pesquisa fundamentar-se-á em análise de literatura específica, principalmente de artigos em idioma estrangeiro, uma vez que o tema "online profiling" ainda não é tratado de forma aprofundada na literatura nacional. A literatura nacional referenciada versará sobre os aspectos do problema apresentado sob a ótica do ordenamento jurídico pátrio (Constituição Federal, Código Civil, Código de Defesa do Consumidor e Projetos de Lei de Proteção de Dados Pessoais).

Objetiva-se desenvolver a análise jurídica dos problemas propostos de forma independente das tecnologias atualmente utilizadas, embora tais tecnologias sirvam de base para a análise dos casos concretos e da apreensão do fato social online profiling tomado em sua generalidade, razão pela qual tais tecnologias serão abordadas sem aprofundamento técnico. 


\subsection{Termos e Definições}

\subsubsection{Online Profiling}

Optou-se, neste trabalho, por adotar a expressão em inglês "online profiling" para denominar o objeto de estudo da dissertação. Desde já, ressalte-se, que a denominação é imprecisa e insuficiente para descrever o objeto em sua complexidade. Decidiu-se adotá-la em razão de sua simplicidade e de sua ampla utilização e compreensão nos meios tecnológicos e jurídicos.

Poder-se-ia cogitar a adoção da denominação traduzida e adaptada para a língua portuguesa: "geração de perfil por conexão na internet", no entanto a longa denominação em vernáculo comprometeria a fluidez do texto além de não resolver os problemas conceituais da denominação original em inglês, os quais passa-se a expor:

Inicialmente, a palavra profiling é um substantivo derivado do verbo inglês "to profile" que significa escrever, desenhar ou produzir uma representação com as principais características de um objeto. É o ato por meio do qual cria-se uma projeção de algo ou de alguém com atributos do objeto que se busca caracterizar. Como dito, esta expressão é insuficiente para traduzir o objeto de análise desta dissertação que, repita-se, vai além da mera geração de um perfil com características do indivíduo. Profiling, neste estudo, deve incorporar uma carga semântica ampla, referindo-se a todo o processo que vai desde a captura de dados pessoais, passando por seu armazenamento, processamento, compartilhamento até sua utilização para a tomada de decisões. É evidente que o termo profiling pode ser interpretado stricto sensu, referindo-se apenas ao tratamento ou processamento de uma massa bruta de dados pessoais cujo resultado são informações úteis para determinados fins. No entanto, na maioria das vezes neste trabalho o termo profiling será usado em seu sentido amplo, qual seja, o já referido processo multifásico de tratamento de dados pessoais.

A expressão "online" é igualmente imprecisa como adjetivo a qualificar o ato que convencionou-se chamar de profiling. Comumente, no contexto das redes 
de computadores, atribui-se ao termo online o significado de simultaneidade, conectividade, disponibilidade, geralmente aplicando-se à possibilidade de imediata transmissão ou recebimento de dados. Em sentido oposto, o termo off-line refere-se, geralmente, à indisponibilidade de conexão ou troca de dados de forma imediata. No contexto do profiling, que ora se analisa, ao adjetivo online deve ser atribuída uma carga semântica diversa: online, nesta seara, deve se referir ao locus do profiling, qual seja, a Internet, ambiente no qual os dados são coletados, ainda que determinadas etapas do processo de profiling - e talvez a maioria delas - como as análises, compartilhamento ou até mesmo a captura de alguns dados podem ser realizadas sem conexão com a internet, ou seja, off-line.

\subsubsection{Dados Pessoais}

Inobstante a multiplicidade de conceitos atribuídos à privacidade, o ponto de interesse para este estudo é a dimensão da privacidade que se relaciona com a proteção dos dados pessoais.

Nesta linha, qualquer iniciativa que objetive a proteção de dados pessoais deve enfrentar a intrigante tarefa de definir o que se entende por "dados pessoais", uma vez que não se pretende proteger todos os tipos de dados, mas tão somente aqueles qualificados como "pessoais".

Observa-se na doutrina, na legislação estrangeira e nos projetos de lei sobre o tema que o conceito de "dados pessoais" está intimamente relacionado à possibilidade de vincular um determinado dado a uma pessoa física. Equivale dizer que se um determinado dado está ou pode ser relacionado a um indivíduo, este dado deve ser considerado, para fins de proteção, um dado pessoal.

Há dados que, tomados isoladamente, têm a capacidade de identificar univocamente o indivíduo que a ele está relacionado. Tome-se, como exemplo, o número da inscrição da pessoa no CPF ou seu número de cadastro numa universidade. No entanto, a maior parte dos dados que podem ser relacionados a um indivíduo dependem do contexto em que estão inseridos para que a identificação com o indivíduo seja possível. Isso porque, tomados isoladamente, 
tais dados não seriam capazes de identificar univocamente a pessoa relacionada ao dado. Como exemplo é possível citar o nome "José da Silva" ou a data de nascimento "25/12/1970", dados que, tomados isoladamente, não são capazes de apontar para um sujeito determinado ao qual estão relacionados.

Desta forma, o adjetivo "pessoal", atribuído ao dado quando este relaciona-se diretamente a um indivíduo, não é atributo intrínseco de um determinado dado considerado isoladamente da massa de dados da qual faz parte. O que faz um dado ser qualificado como "pessoal" é sua relação de pertinência com uma massa de dados relacionada a um indivíduo identificado ou identificável.

Há duas linhas para conceituar "dados pessoais": uma restritiva e outra mais abrangente. De acordo com a interpretação restritiva, um dado é qualificado como pessoal se é possível, de imediato, identificar o indivíduo a ele relacionado. Neste caso convencionou-se dizer que o dado é relacionado à pessoa "identificada". Já a interpretação abrangente qualifica um dado como pessoal se existe a possibilidade de identificar a pessoa a ele relacionada, embora, de imediato, tal relacionamento não se observe. Neste caso, diz-se que o dado é relacionado a pessoa "identificável".

Dados que, por natureza, referem-se de alguma maneira a indivíduos como, por exemplo, estado civil, religião e domićlio, mas que num determinado contexto não podem ser relacionados imediatamente a uma pessoa identificada, são denominados "dados anônimos", o que, a princípio, excluiria tais dados do escopo protetivo das já referidas iniciativas legislativas. No entanto, como demonstrar-se-á adiante, ainda que num determinado contexto os dados não possam ser imediatamente relacionados a um indivíduo, a agregação de mais dados àquela massa de dados poderá tornar a identificação possível. Equivale dizer que num momento inicial o dado pode ter relação de pertinência com uma massa de dados que não identifica um indivíduo, mas num momento posterior pode haver a agregação de novos dados identificáveis a esta massa de dados outrora não relacionada ao indivíduo fazendo com que o dado inicialmente relacionado a uma massa de dados não identificada com o indivíduo passe a se relacionar com um 
novo conjunto de dados que permita a identificação do indivíduo. A este processo de agregação de dados que passa a permitir a identificação do sujeito relacionado aos dados convencionou-se chamar de desanonimização.

Em face da comprovada possibilidade de desanonimização, neste estudo a expressão "dados pessoais" deverá ter um sentido amplo não abrangendo apenas aqueles dados que permitam identificar imediatamente 0 sujeito relacionado ao dado.

O conceito de "dados pessoais", no contexto do "online profiling", deve admitir um sentido que inclua dados de comportamento online, ou seja, dados que, de forma mais precisa, dinâmica e incremental, têm o potencial revelar aspectos da personalidade do indivíduo que muitas vezes até as pessoas mais próximas dele desconhecem. Tome-se, como exemplo, um indivíduo que descobre ser portador de uma doença ou é adepto de uma determinada prática sexual, fatos que por razões de intimidade, prefere ocultar das pessoas que com ele têm uma relação de maior intimidade. Tais aspectos de sua intimidade são facilmente capturados por meio da coleta de dados de navegação (online behavior) e, portanto, tais dados devem ser considerados "dados pessoais" ainda que a base de dados não contenha dados que possibilitem a imediata identificação do sujeito. Pois, como já mencionado anteriormente, a identificação da pessoa relacionada aos dados pode ocorrer em momento posterior ao da coleta.

O comportamento online de um indivíduo, consubstanciado em pesquisas em motores de busca, visita a sites especializados, aquisições em lojas de comércio eletrônico, deslocamento geográfico, entre outros, poderá ser - e, de fato, é - monitorado pelas empresas de internet de modo que os dados de navegação (URLs visitadas, buscas realizadas e produtos adquiridos ou pesquisados) são incluídos em bases de dados que estarão à disposição da empresa que os coletou e das empresas com as quais ela compartilhará os dados coletados. Ademais, inclua-se neste rol os dados de localização geográfica do usuário, dados sobre seus relacionamentos na internet (outros usuários com os quais ele está conectado) e tudo de forma incremental, ou seja, as empresas que 
coletam os dados mantêm um histórico sempre crescente que permite, por meio de análises cada vez mais precisas, prever determinadas ações ou situações envolvendo a pessoa relacionada aos dados ${ }^{8}$.

É fato que boa parte dos dados de comportamento online coletados por estas empresas de internet num momento inicial pode não estar relacionada diretamente a um indivíduo, mas tão somente ao um endereço de conexão denominado endereço IP. No entanto, a ulterior associação de um endereço IP a um indivíduo permite que boa parte da massa de dados de navegação coletada para aquele IP seja atribuída ao indivíduo associado ao IP. Essa associação de endereço IP com um indivíduo ocorre com bastante frequência, principalmente num cenário onde se observa uma tendência decrescente na utilização de dispositivos compartilhados (desktops) e um aumento de dispositivos utilizados por apenas uma pessoa (dispositivos móveis). ${ }^{9}$

Por fim, destaque-se que a massa de dados pessoais coletada e atribuída a um indivíduo pode ser analisada e processada de modo a gerar dados derivados, também considerados como dados pessoais. Note-se que os dados derivados destas análises, dados que compõem o que convencionamos denominar de profile, não apenas consistirão de dados que refletem aspectos relacionados ao passado do sujeito, mas também ao seu futuro, na medida em que a massa de dados processada poderá sugerir categorias, tendências e prever condutas do indivíduo.

${ }^{8}$ Evita-se, neste ponto, fazer referência ao sujeito do qual os dados são obtidos como "titular dos dados". Por esta razão é dada a preferência à expressão "pessoa ou sujeito relacionado aos dados", por mais imprecisa que possa parecer. A possível relação de "titularidade" entre os sujeitos e os dados é questão que será discutida posteriormente nesta dissertação.

${ }^{9}$ Em termos práticos bastaria, por exemplo, a autenticação de um usuário a um serviço de internet (e.g. efetuar login no Facebook ou no Google) para que a empresa de internet associe o IP ao indivíduo. Esta associação é na maioria das vezes imediata pois os usuários dos serviços do Facebook e do Google geralmente acionam a opção para se manterem "logados" nestes serviços evitando que lhes seja exigida a senha todas as vezes que acessarem os serviços. 
Além destes dados comportamentais coletados por rastreamento, também consideramos como "dados pessoais" todas as informações geradas como resultado do processamento dos dados brutos coletados. Nesta categoria são incluídos, por exemplo, dados de rating de crédito, nível de risco para contratação de seguros e graus de potencial interesse para aquisição de produtos ou serviços.

\subsubsection{Sujeitos Relacionados aos Dados}

Os usuários de internet que têm seus dados pessoais capturados por empresas de internet são denominados, na literatura estrangeira, de "data subjects". Esta denominação consta nas versões em inglês da Diretiva 95/46/CE ${ }^{10}$ e do novo Regulamento de Proteção de Dados Pessoais ${ }^{11}$ que unificou os dispositivos sobre a matéria na União Europeia. No entanto, na versão em língua portuguesa consta a expressão "titulares dos dados". Os projetos de lei que tramitam em nosso país também adotaram a expressão "titular dos dados" para se referirem à pessoa física à qual os dados estão relacionados.

Embora a expressão "titulares dos dados", adotada em Portugal e no Brasil, seja mais concisa do que aquela que ora apresentamos - "sujeitos relacionados aos dados" - evitou-se, neste trabalho, adotar o termo "titulares" por conta da afinidade deste termo com o conceito de "propriedade" ou de outros direitos. Quem é titular, é titular de algum direito. No caso, os dados pessoais não são direitos para que sobre eles se exerça titularidade, entendida aqui no sentido de propriedade. Tais dados podem ser objetos de direito, havendo, portanto, direitos que podem ser exercidos sobre os dados pessoais, o que faz da pessoa relacionada aos dados, titular destes direitos (e.g. direito de não publicação, direito de esquecimento, direito de não compartilhamento com terceiros, etc...). No

10 Directive 95/46/EC on the protection of individuals with regard to the processing of personal data and on the free movement of such data (Data protection directive). 24.out.1995.

11 Regulation 2016/679 on the protection of natural persons with regard to the processing of personal data and on the free movement of such data, and repealing Directive 95/46/EC (General Data Protection Regulation). 27.abr.2016. 
entanto, neste ponto não nos parece claro que um indivíduo seja titular dos mesmos direitos sobre todos os dados relacionados a si. Tome-se como exemplo o direito de não ter um determinado dado compartilhado com terceiros. Parece evidente que um dado como número de cartão de crédito ou renda mensal de um indivíduo não deveria ser compartilhado sem seu consentimento. No entanto o mesmo não pode ser dito em relação a dados públicos que podem ser encontrados nos cartórios de registro civil ao alcance de qualquer interessado como, por exemplo, estado civil e data de nascimento.

Portanto, ao se dizer "titular dos dados pessoais" não está claro, a priori, quais são os direitos relacionados a esta titularidade. Por tais razões, nesta dissertação optou-se pela expressão "pessoa ou sujeito relacionado aos dados".

\subsection{Classificação dos Dados Pessoais}

Os dados pessoais podem ser classificados em relação a diversos critérios. Este estudo se limita a apresentar as classificações que oferecem um resultado prático no âmbito da análise do online profiling.

O primeiro critério de classificação dos dados pessoais é o grau de intimidade do aspecto da personalidade refletido pelo dado pessoal. Características pessoais muito íntimas são classificadas como "dados pessoais sensíveis". Nesta categoria comumente são incluídos dados como ideologia política, etnia, convicções religiosas, opções e preferências sexuais. Em decorrência da projeção de aspectos da personalidade com alto grau de intimidade, observa-se que os instrumentos de tutela conferem a estes dados maior grau de proteção.

O segundo critério de classificação dos dados pessoais está relacionado à possibilidade de identificação do sujeito a partir de um conjunto de dados. Denomina-se "dados anônimos" o conjunto de dados a partir do qual não é possível, de imediato, identificar o sujeito relacionado aos dados. A rigor, o atributo "anônimo" não é intrínseco de um determinado dado, mas de uma massa de dados tomada isoladamente. Equivale dizer que se a partir de um conjunto de dados não for possível identificar de forma imediata o indivíduo relacionado aos dados, a este conjunto de dados é atribuída a denominação de "dados anônimos". No entanto, 
esta classificação não é estática, ou seja, um conjunto de dados pode ser, num determinado momento, insuficiente para identificar o sujeito relacionado a ele, mas havendo posterior agregação de mais dados ao conjunto ou a partir de correlação com outras fontes de dados, pode ocorrer o fenômeno que convencionou-se chamar de "desanonimização". Da mesma forma, um conjunto de dados não anônimo, ou seja, cujos sujeitos são identificados, pode ser submetido a um processo de deidentificação ou anonimização gerando um conjunto de dados anônimos. ${ }^{12}$

Portanto, o atributo "anônimo", quando vinculado a um conjunto de dados, deve ser encarado como instável. Por tal razão, as iniciativas legislativas não deveriam, em abstrato, atribuir um nível de proteção menor ao conjunto de dados anônimo tendo-se em vista a possibilidade de reidentificação dos sujeitos relacionado aos dados. O Anexo I deste trabalho contém exemplos clássicos de desanonimização que suscitaram a discussão pública sobre a crença na proteção de dados por meio da anonimização.

No âmbito no processo de online profiling, os dados pessoais podem ser também classificados em função da iniciativa do fornecimento dos dados. Denomina-se "dados voluntários" aqueles dados que são voluntariamente fornecidos pelo sujeito com total consciência de que dados estão sendo transmitidos num determinado momento. Como exemplo, cita-se os dados fornecidos por um consumidor durante o preenchimento de um formulário de cadastro num website: nome, endereço eletrônico, endereço físico, documento de identificação e número de cartão de crédito são exemplos de dados voluntariamente fornecidos pelo usuário. Em contrapartida, os "dados não voluntários" são aqueles capturados ou produzidos pelas empresas de internet sem a imediata ciência do sujeito em relação à natureza e o momento em que o dado

12 A seção 4.2 deste trabalho abordará com mais detalhes a questão da anonimização e desanonimização de conjunto de dados. 
está sendo capturado ou produzido. Como exemplo de dados não voluntários citase os dados de navegação, dados referentes às pesquisas realizadas em sites de busca, dados do dispositivo, da conexão de internet e dados derivados de análises.

Os dados não voluntários admitem uma subclassificação em relação à sua origem. Podemos classificar estes dados em dados de navegação, dados de dispositivo, dados de conexão e dados derivados, sem prejuízo de outras espécies.

Os dados de navegação consistem no histórico de navegação (browsing history) do usuário. Dentre estes dados estão os sites visitados, os links clicados e as pesquisas em motores de busca. Dados de navegação são sistematicamente coletados por empresas de internet e gravados no perfil do usuário. É por esta razão que um usuário após consultar um determinado produto num site de comércio eletrônico usando seu dispositivo móvel, pode ser surpreendido com uma propaganda do mesmo produto em seu computador pessoal no feed de notícias do Facebook em outro dispositivo, no seu computador pessoal, por exemplo.

Os dados de dispositivo incluem informações sobre o hardware e software do dispositivo utilizado na navegação. Isto inclui sistema operacional e sua versão. Houve casos em que a identificação do sistema operacional foi utilizada pelas empresas de internet como fator decisivo para a apresentação de ofertas e definição de preços. A Orbitz, empresa de reservas online, utilizando técnicas de mineração de dados, descobriu que os usuários dos dispositivos da Apple gastavam, em média, 30\% a mais nos hotéis em comparação aos usuários de PC. A partir desta conclusão a Orbitz passou a exibir opções mais sofisticadas e caras na sua primeira página para os usuários de Apple. ${ }^{13}$

13 The Wall Street Journal. On Orbitz, Mac Users Steered to Pricier Hotels. Disponível em: <http://www.wsj.com/articles/SB10001424052702304458604577488822667325882>. Acesso em: 04.nov.2017. 
A Google admite que coleta informações do dispositivo utilizado para a navegação bem como informações de conexão como o endereço IP:

Quando você acessa nossos serviços (por exemplo, faz uma pesquisa no Google, recebe rotas no Google Maps ou assiste um vídeo no YouTube), coletamos dados para fazer com que esses serviços funcionem melhor para você. Isso pode incluir:

- Coisas que você pesquisa

- Sites que você visita

- Vídeos a que você assiste

- Anúncios nos quais você clica ou toca

- Seu local

- Informações do dispositivo

- Endereço IP e dados de cookies ${ }^{14}$

Os dados derivados merecem atenção especial pois sua origem está no processamento e correlação da massa de dados obtida pelas empresas de internet. São dados que não são coletados, mas produzidos por algoritmos e ferramentas de análise podendo conter, em seu bojo, elementos de decisão automática como, por exemplo, credit scoring ou nível de risco para a contratação de seguro.

Embora as classificações acima tenham sido utilizadas no estabelecimento de normas de proteção (e.g. dados sensíveis recebem maior grau de proteção enquanto dados anônimos recebem menor grau de proteção), a nova realidade envolvendo o Big Data e o online profiling acabam por minorar a diferença entre os diversos tipos de dados fazendo com que a proteção mereça ser aplicada em todos os casos. Neste sentido lecionou Stefano RodotÀ:

O ponto de vista global torna a se impor nos temas ligados ao tratamento a ser reservado aos dados pessoais e àqueles anônimos ou agregados, à distinção entre privacidade individual e

${ }^{14}$ GOOGLE. Seus dados. Disponível em: <https://privacy.google.com/your-data.html>. Acesso em: 26.nov.2017. 
de grupo. Diante da nova realidade dos "perfis", essas distinções perdem significado: seja porque dados pessoais, aparentemente não "sensíveis", podem se tornar sensíveis se contribuem para a elaboração de um perfil; seja porque a própria esfera individual pode ser prejudicada quando se pertence a um grupo do qual tenha sido traçado um perfil com conotações negativas. ${ }^{15}$

15 RODOTÀ, Stefano. A vida na sociedade da vigilância: a privacidade hoje. Organização, seleção e apresentação de Maria Celina Bodin de Moraes. Tradução: Danilo Doneda e Luciana Cabral Doneda. Rio de Janeiro: Renovar, 2008. p. 84. 


\section{CONCLUSÃO}

A evolução tecnológica municiou a sociedade com ferramentas que permitem a captura, armazenamento e transmissão de dados de forma mais rápida e em maior quantidade. Se por um lado o rápido progresso da tecnologia digital trouxe facilidade e conectividade, por outro lado colocou em posição de extrema vulnerabilidade determinados direitos do indivíduo.

O direito à privacidade, neste contexto, ganhou nova dimensão: o direito à proteção dos dados pessoais. Diversas normas foram elaboradas na tentativa de proteger os indivíduos da atividade de entidades públicas e privadas que capturam, armazenam, utilizam e compartilham dados pessoais. No entanto, na medida em que se observa um passo adiante na evolução tecnológica, o anacronismo das normas em vigor fica evidente.

A possibilidade de rastreamento do comportamento online aliado à grande capacidade de armazenamento e de processamento de dados (Big Data) permite às empresas de internet a elaboração de perfis dos usuários que refletem, de forma cada vez mais precisa, aspectos de sua personalidade, inclusive os aspectos mais íntimos.

O novo cenário coloca em cheque as premissas e conceitos tidos como verdadeiros pelos legisladores que elaboraram as normas de proteção de dados pessoais. Os conceitos de dados pessoais como aqueles que estão relacionados a um indivíduo identificado ou identificável pode estar superado diante da primazia da identificação da conexão. A premissa da anonimização e do consentimento informado também não estão livres das críticas.

O cenário é preocupante, na medida em que a utilização dos perfis gerados pelas empresas de internet pode transcender a mera veiculação de propaganda adequada ao perfil e invadir dimensões que afetem a esfera jurídica do sujeito relacionado aos dados. A discriminação decorrente de decisão exclusivamente automatizada é um exemplo dos resultados da má utilização dos perfis gerados na análise de dados pessoais. 
A solução para a prevenção de danos aos indivíduos não deve estar limitada a um conteúdo meramente normativo. A auto-regulação setorial, a instituição de um órgão de controle e fiscalização bem como a conscientização dos usuários de internet são parte do framework protetivo. 


\section{ANEXO I: EXEMPLOS DE DESANONIMIZAÇÃO}

Diversas normas de proteção de dados pessoais são elaboradas sob a premissa de que se um conjunto de dados for anonimizado, então a este conjunto podem ser aplicadas regras menos rigorosas diante da suposta impossibilidade de identificação do sujeito relacionado aos dados.

Este anexo apresenta alguns casos que se tornaram públicos de conjuntos de dados originalmente anônimos que, após disponibilizados ao público, sofreram um processo de desanonimização causando não apenas constrangimento para as empresas que fizeram a publicação bem como o enfraquecimento da premissa exposta no parágrafo anterior.

\subsection{Pesquisas do Motor de Buscas da America Online (AOL)}

Em agosto de 2006 a America Online, pretendendo estabelecer uma comunidade de pesquisa aberta, divulgou na internet uma lista de 20.000 .000 (vinte milhões) de pesquisas feitas no seu motor de busca por 657.000 (seiscentos e cinquenta e sete mil) usuários nos três meses anteriores.

Evidentemente os dados foram alterados pela $\mathrm{AOL}$ antes da divulgação apenas para ocultar o nome e o IP (Internet Protocol Address) dos usuários que fizeram as pesquisas. Em substituição aos dados que permitiriam uma identificação imediata do usuário, a empresa atribuiu um código numérico sequencial para cada usuário de modo que os pesquisadores que fossem analisar os dados pudessem agrupar todas as pesquisas feitas por um determinado usuário.

Não tardou para que uma série de publicações surgissem com fatos curiosos sobre os indivíduos por trás das pesquisas. Foram encontradas as seguintes pesquisas realizadas pelo usuário ao qual foi atribuído o código 17556639: "Como matar sua esposa", "Fotos de pessoas mortas", "Imagens de acidentes de carro".

Um caso que demonstrou a fragilidade da anonimização foi o do usuário 4417749. Dentre as pesquisas deste usuário estavam as seguintes: "paisagistas em Lilburn, GA", "casas vendidas em shadow lake subdivision gwinnett county 
georgia", várias pesquisas com nomes de pessoas com sobrenome Arnold e "cachorros que fazem xixi em tudo". Não foi necessário muito tempo para que a identidade deste usuário fosse revelada. Tratava-se de Thelma Arnold, uma viúva de 62 anos que vivia em Lilburn, Georgia. Ao ser entrevistada por um repórter a Sra. Arnold admitiu que as pesquisas elencadas sob o código 4417749 eram realmente dela. ${ }^{164}$

Diante do evidente fracasso na anonimização a $\mathrm{AOL}$ removeu os dados, desculpou-se com a comunidade e foi processada numa class action onde pleiteouse 5 mil dólares para cada usuário que teve seus dados divulgados. A falha por excesso de confiança na anonimização também custou o cargo do CTO (Chief Technology Officer) da AOL que renunciou duas semanas após a divulgação. ${ }^{165}$

\subsection{Massachusetts Group Insurance Commission (GIC)}

Em meados da década de 90, a agência governamental $\mathrm{GCl}$ de Massachusetts, objetivando apoiar pesquisas em benefício da sociedade, divulgou uma lista de registros médicos de pacientes que visitaram os hospitais estaduais com informações sobre diagnósticos e prescrições. Antes da divulgação, no entanto, os dados que permitiriam a identificação dos pacientes foram removidos (nome, social security code, endereço e outros). No entanto, aproximadamente uma centena de atributos foram mantidos.

LATANYA SWEENEY, que na época cursava seu PhD no MIT, conseguiu demonstrar que, apesar da tentativa de anonimização por supressão de identificadores, outros atributos poderiam ser utilizados para identificar os pacientes. Com apenas $U \$ 20,00$, Latanya adquiriu um $C D$ com uma base de dados dos eleitores de Cambridge onde constavam nome, data de nascimento, CEP e

164 The New York Times Website. A Face Is Exposed for AOL Searcher No. 4417749. Disponível em: <http://query.nytimes.com/gst/abstract.html?res=9E0CE3DD1F3FF93AA3575BC0 A9609C8B63>

165 The New York Times Website. AOL executive quits after posting of search data Technology - International Herald Tribune. Disponível em: <http://www.nytimes.com/2006 /08/22/technology/22iht-aol.2558731.html> 
sexo. Ao correlacionar estas informações com a base de dados do $\mathrm{GCl}$, Latanya conseguiu identificar os dados médicos do governador de Massachusetts, William Weld, incluindo diagnósticos e prescrições médicas. A pesquisadora fez questão de enviar ao governador as informações relacionadas a ele que foram reidentificadas.

Posteriormente LATANYA SWEENEY, após o processamento do censo de 1990, chegou à conclusão de que $87 \%$ das pessoas pode ser identificada apenas utilizando-se do trio de informações CEP, data de nascimento e sexo. ${ }^{166}$

Sob a coordenação de Latanya Sweeney, o Data Privacy Lab de Harvard disponibilizou um website (http://aboutmyinfo.org/) onde é possível verificar quão facilmente um morador dos Estados Unidos poderá ser reidentificado em função do trio CEP, data de nascimento e sexo.

\subsection{Caso Netflix}

O Prêmio Netflix (Netflix Prize) foi uma competição patrocinada pela Netflix, empresa de entretenimento e vídeo sob demanda. A proposta da competição era o desenvolvimento de algoritmo que, baseado em dados de avaliação de usuários sobre filmes e sua correlação, pudesse prever qual seria a avaliação destes usuários em relação a outros filmes. O objetivo do algoritmo seria, portanto, permitir que a empresa sugerisse os melhores filmes para seus usuários.

Para fins de desenvolvimento do algoritmo, a Netflix disponibilizou publicamente uma base de dados de 100 milhões de avaliações de filmes feitas por 500 mil usuários. Antes de sua publicação, a base de dados foi anonimizada, ou seja, foram removidos todos os dados que pudessem identificar o usuário,

166 SWEENEY, Latanya. k-Anonymity: a model for protecting privacy. Maio, 2002.

Disponível em: <https://epic.org/privacy/reidentification/Sweeney_Article.pdf>. Acesso em: 07.dez.2017. p. 2. 
permanecendo apenas um identificador numérico para cada usuário a fim de relacionar a avaliação de todos os filmes assistidos por este usuário agora anônimo.

Dois pesquisadores da Universidade do Texas (Austin) ${ }^{167}$ foram capazes de reidentificar vários usuários por meio de correlação com as avaliações destes mesmos usuários publicadas em outra base de dados de filmes, o IMDb (Internet Movie Database). Esta reidentificação foi possível em razão da correlação de dados tais como datas das avaliações e filmes que não estão entre os mais assistidos.

Este episódio demonstrou a fragilidade do conceito de que uma vez anonimizados os dados estão protegidos. Também demonstrou a possibilidade de produção de dados derivados sensíveis por meio de dedução ou inferência. Neste sentido, observa-se, ao final do relatório destes pesquisadores que eles puderam deduzir aspectos sensíveis da personalidade dos indivíduos reidentificados em face das avaliações atribuídas a determinados títulos:

First, we can immediately find his political orientation based on his strong opinions about "Power and Terror: Noam Chomsky in Our Times" and "Fahrenheit 9/11." Strong guesses about his religious views can be made based on his ratings on "Jesus of Nazareth" and "The Gospel of John". He did not like "Super Size Me" at all; perhaps this implies something about his physical size? Both items that we found with predominantly gay themes, "Bent" and "Queer as folk" were rated one star out of five. He is a cultish follower of "Mystery Science Theater 3000". This is far from all we found about this one person, but having made our point, we will spare the reader further lurid details. ${ }^{168}$

Em razão deste episódio uma ação judicial foi proposta em 2009 contra a Netflix baseada no VPPA, Video Privacy Protection Act de 1988, lei que proíbe a divulgação de dados de locação ou aquisição de vídeos. A partir de então a Netflix cancelou as edições seguintes do Netflix Prize.

167 NARAYANAN, Arvind; SHMATIKOV, Shmatikov. How to break anonymity of the netflix prize dataset. 2006. Disponível em: <https://arxiv.org/abs/cs/0610105>. Acesso em: 05.jun.2017.

168 Ibidem, p. 16 


\section{REFERÊNCIAS BIBLIOGRÁFICAS}

\subsection{LIVROS E MONOGRAFIAS}

BITTAR, Carlos Alberto. Os direitos da personalidade. $8^{\mathrm{a}}$ ed., São Paulo: Saraiva, 2015.

CUPIS, Adriano de. Os direitos da personalidade. Tradução de Afonso Celso Furtado Rezende. 2ª ed., São Paulo: Quorum, 2008.

DONEDA, Danilo. Da privacidade à proteção de dados pessoais. Rio de Janeiro: Renovar, 2006.

LEONARDI, Marcel. Tutela e privacidade na internet. São Paulo: Saraiva, 2012.

LIMA, Cíntia Rosa Pereira de. A imprescindibilidade de uma entidade de garantia para a efetiva proteção dos dados pessoais no cenário futuro do Brasil. 487 p. Tese de Livre Docência. Faculdade de Direito Ribeirão Preto/USP. 2015.

MARTINS, Ives Gandra da Silva; PEREIRA JÚNIOR, Antônio Jorge (Coord.). Direito à privacidade. Aparecida, SP: Ideias \& Letras; São Paulo: Centro de Extensão Universitária, 2005.

REALE, Miguel. Lições preliminares de direito. $25^{\mathrm{a}}$ ed. São Paulo: Saraiva. 2001.

RODOTÀ, STEFANO. A vida na sociedade da vigilância: a privacidade hoje. Organização, seleção e apresentação de Maria Celina Bodin de Moraes. Tradução: Danilo Doneda e Luciana Cabral Doneda.. Rio de Janeiro: Renovar, 2008.

ROOSENDAAL, Arnold. We Are All Connected to Facebook . . . by Facebook! in: S. Gutwirth et al. (eds.), European Data Protection: In Good Health?, Heidelberg: Springer, 2012, pp. 3-19. 


\subsection{ARTIGOS E PARECERES}

ALTAWEEL, Ibrahim; GOOD, Nathan; HOOFNAGLE, Chris Jay. Privacy on Adult Websites. Workshop on Technology and Consumer Protection (ConPro '17), co-located with the 38th IEEE Symposium on Security and Privacy, San Jose, CA (2017). Disponível em: <https://ssrn.com/abstract=2851997>. Acesso em: 11.abr.2017.

BORGESIUS, Frederik Zuiderveen. Behavioral targeting: A european legal perspective, IEEE Security \& Privacy, vol.11, no. 1, pp. 82-85, Jan.-Feb. 2013, Disponível em: <http://ssrn.com/abstract=2287956> Acesso em: 02.dez.2017

CRAWFORD, Kate; SCHULTZ, Jason. Big Data and Due Process: Toward a Framework to Redress Predictive Privacy Harms. Boston College Law Review, v. 55, no 93, 2014; NYU School of Law, Public Law Research Paper №. 1364; NYU Law and Economics Research Paper No. 13-36. Disponível em: <http://ssrn.com/abstract=2325784> Acesso em: 02.dez.2017.

FAIRFIELD, Joshua A.T. Do-Not-Track as Default. Northwestern Journal of Technology and Intellectual Property, Vol. 11, No. 7, 2013. Disponível em: <http://ssrn.com/abstract=2338028>. Acesso em: 01.nov.2017.

FEDERAL TRADE COMMISSION. Data brokers: a call for transparency and accountability. Maio 2014. Disponível em: <https://www.ftc.gov/system/files/ documents/reports/data-brokers-call-transparency-accountability-report-federaltrade-commission-may-2014/140527databrokerreport.pdf>. Acesso em: 25.abr.2017

HEEGER, Eva. Controlling Your Online Profile: Reality or an Illusion? A Research into Informed Consent as a Mechanism to Regulate Commercial Profiling. 2005. Disponível em: <http://ssrn.com/abstract=2658651>. Acesso em: 12.dez.2017.

LEONARDI, Marcel. Dados pessoais, regulação e a economia digital. Jornal da Tarde. 28.03.2011. p. 2. Disponível em: <http://leonardi.adv.br/2011 /03/dados-pessoais-regulacao-e-a-economia-digital/>. Acesso em: 05.dez.2017. 
LIMA, Cíntia Rosa Pereira de. O ônus de ler o contrato no contexto da "ditadura" dos contratos de adesão eletrônicos. In: Direito e novas tecnologias I [Recurso eletrônico online] CONPEDI/UFPB (org.) ROVER, Aires José; CELLA, José Renato Graziero; AYUDA, Fernando Galindo. Florianópolis: CONPEDI, 2014. pp. 343-365. Disponível em: <http://publicadireito.com.br/artigos/?cod= 981322808aba8a03>. Acesso em: 02.dez.2017.

LIMA, Cíntia Rosa Pereira de. Parecer Técnico encaminhado pela Professora Livre Docente de Direito Civil da Faculdade de Direito de Ribeirão Preto/USP, Dra. Cíntia Rosa Pereira de Lima à Comissão Especial da Câmara dos Deputados que proferirá parecer sobre o Projeto de Lei n. 4.060, de 2012, do Deputado Milton Monti, que dispõe sobre o Tratamento de Dados Pessoais. Ribeirão Preto: 2017. Disponível em: <http://www2.camara.leg.br/atividadelegislativa/comissoes/comissoes-temporarias/especiais/55a-legislatura/pl-4060-

12-tratamento-e-protecao-de-dados-pessoais/documentos/outrosdocumentos/dra-cintia-rosa-pereira-de-lima-usp>. Acesso em: 05.dez.2017.

MACCLURG, Andrew J., A Thousand Words Are Worth a Picture: A Privacy Tort Response to Consumer Data Profiling. Northwestern University Law Review, v. 98. p. 63-133, 2003. Disponível em: <http://papers.ssrn.com/ sol3/papers.cfm?abstract_id=1628724> Acesso em: 02.dez.2017

MAYER, Jonathan R.; MITCHELL, John C. Third-Party Web Tracking: Policy and Technology, Proceedings of the 2012 IEEE Symposium on Security and Privacy, p.413-427, May 20-25, 2012. Disponível em: $<$ https://jonathanmayer.org/papers_data/trackingsurvey12.pdf>. Acesso em: 07.dez.2017.

MITCHELL, I. D. Third-Party Tracking Cookies and Data Privacy. abr. 2012. Disponível em: <https://papers.ssrn.com/sol3/papers.cfm? abstract_id=2058326 >. Acesso em: 11.dez.2017. 
NARAYANAN, Arvind; SHMATIKOV, Shmatikov. How to break anonymity of the netflix prize dataset. 2006. Disponivel em: <https://arxiv.org/abs/cs/0610105>. Acesso em: 05.dez.2017.

OHM, Paul. Broken promises of privacy: responding to the surprising failure of anonymization. UCLA Law Review, Vol. 57, p. 1701-1777, 2010. Disponível em <http://www.uclalawreview.org/broken-promises-of-privacyresponding-to-the-surprising-failure-of-anonymization-2>. Acesso em: 12.dez.2017

PROSSER, William L. Privacy. California Law Review. Volume 48. Issue 3. 1960. p. 383-423 Disponível em: <http://scholarship.law.berkeley.edu/cgi/ viewcontent.cgi?article $=3157 \&$ context=californialawreview $>$. Acesso em: 12.dez.2017.

REINALDO FILHO, Demócrito. A Diretiva Europeia sobre proteção de dados pessoais. Revista Jus Navigandi, Teresina, ano 18, n. 3507, 6 fev. 2013. Disponível em: <https://jus.com.br/artigos/23669>. Acesso em: 07.dez.2017.

SHAH, Rajiv C.;KESAN, Jay P. Recipes for cookies: How institutions shape communication technologies. Illinois Public Law and Legal Theory Research Papers Series No. 01-14. pp. 315-336. Disponível em: $<$ https://experts.illinois.edu/en/publications/recipes-for-cookies-how-institutionsshape-communication-technolo>. Acesso em: 05.dez.2017

SKOUMA, Georgia; LÉONARD, Laura. On-line behavioral tracking: What may change after the legal reform on personal data protection. In: GUTWIRTH, Serge; LEENES, Ronald; DE HERT, Paul (Eds). Reforming european data protection law. Springer, 2015. pp. 35-60.

SOLOVE, Daniel J.. Conceptualizing Privacy. California Law Review, v. 90, p. 1087, julho/2002. Disponível em: <http://scholarship.law.berkeley.edu/ californialawreview/vol90/iss4/2/>. Acesso em: 02.dez.2017 
SWEENEY, Latanya. k-Anonymity: a model for protecting privacy. Maio, 2002. Disponível em: <https://epic.org/privacy/reidentification/Sweeney_ Article.pdf>. Acesso em: 07.dez.2017

SWIRE, Peter. Markets, Self-Regulation, and Government Enforcement in the Protection of Personal Information. 1997. Disponível em: <https://ssrn.com/abstract=11472>. Acesso em: 25.nov.2017.

TENE, Omer; POLONETSKY, Jules. Privacy in the age of big data: a time for big decisions, Stanford Law Review Online 64. p. 63-69, 2012. Disponível em: <http://www.stanfordlawreview.org/online/privacy-paradox/big-data> Acesso em: 02.dez.2017

WARREN, Samuel D.; BRANDEIS, Louis D.. The Right to Privacy. 4 HARV.L.REV. 193 1890. Disponível em: <http://faculty.uml.edu/sgallagher/ Brandeisprivacy.htm>. Acesso em: 01.dez.2017

WORLD ECONOMIC FORUM. Personal Data: The Emergence of a New Asset Class. Cologny/Geneva, Switzerland, 2011. Disponível em: $<$ http://www3.weforum.org/docs/WEF_ITTC_PersonalDataNewAsset_Report_201 1.pdf $>$. Acesso em: 11.dez.2017.

\subsection{RELATÓRIOS}

ALTAWEEL, Ibrahim; GOOD, Nathan; HOOFNAGLE, Chris Jay. Web Privacy Census (December 15, 2015). Technology Science. 2015121502, Online. Disponível em: <https://ssrn.com/abstract=2703814>. Acesso em: 04.dez.2017.

FTC - Federal Trade Commission. Protecting consumer privacy in an era of rapid change. 2012. Disponível em: <https://www.ftc.gov/sites/default/files/ documents/reports/federal-trade-commission-report-protecting-consumer-privacyera-rapid-change-recommendations/120326privacyreport.pdf>. Acesso em: 14.nov.2017.

FTC - Federal Trade Commission. Self-regulation and privacy online: a report to congress. 1999. Disponível em: <https://www.ftc.gov/system/files/ 
documents/reports/self-regulation-privacy-onlinea-federal-trade-commissionreport-congress/1999self-regulationreport.pdf>. Acesso em: 14.nov.2017.

PCAST - President's Council of Advisors on Science and Technology. Big data and privacy: A technological perspective. 2014. Disponível em: <https://obamawhitehouse.archives.gov/sites/default/files/microsites/ostp/PCAST/ pcast_big_data_and_privacy_-_may_2014.pdf>. Acesso em: 05.dez.2016. ${ }^{169}$

PURCELL, Kristen; BRENNER, Joanna; RAINIE, Lee. Search Engine Use 2012. Disponível em: <http://www.pewinternet.org/files/old-media/Files/ Reports/2012/PIP_Search_Engine_Use_2012.pdf>. Acesso em: 01.dez.2017.

\subsection{LEGISLAÇÃO}

BRASIL. PLS 131/2014. Dispõe sobre o fornecimento de dados de cidadãos ou empresas brasileiros a organismos estrangeiros. Disponível em: <https://www25.senado.leg.br/web/atividade/materias/-/materia/116969>. Acesso em: 11.dez.2017.

BRASIL. PLS 181/2014. Estabelece princípios, garantias, direitos e obrigações referentes à proteção de dados pessoais. Disponível em: <https://www25.senado.leg.br/web/atividade/materias/-/materia/117736>. Acesso em: 11.dez.2017.

BRASIL. PLS 330/2013. Dispõe sobre a proteção, o tratamento e o uso dos dados pessoais, e dá outras providências. Disponível em: <https://www25.senado.leg.br/web/atividade/materias/-/materia/113947>. Acesso em: 11.dez.2017.

169 O site que hospedava o referido relatório (obamawhitehouse.archives.gov) foi removido em meados de 2017. A íntegra do documento pode ser acessada no seguinte link: http://www.nicotra.com.br/wp-content/uploads/pdf/pcast_big_data_and_privacy_-_may_2014.pdf 
BRASIL. PL 4060/2012. Dispõe sobre o tratamento de dados pessoais, e dá outras providências. Disponível em: <http://www.camara.gov.br/proposicoes Web/fichadetramitacao?idProposicao=548066> . Acesso em: 12.dez.2017.

BRASIL. PL 5276/2016. Dispõe sobre o tratamento de dados pessoais para a garantia do livre desenvolvimento da personalidade e da dignidade da pessoa natural. Disponível em: <http://www.camara.gov.br/proposicoesWeb/ fichadetramitacao?idProposicao=2084378>. Acesso em: 11.dez.2017.

EUROPEAN PARLIAMENT AND COUNCIL. Directive 2002/58/EC concerning the processing of personal data and the protection of privacy in the electronic communications sector (Directive on privacy and electronic communications). 12.jul.2002. Disponível em: <http://eur-lex.europa.eu/LexUriServ/ LexUriServ.do?uri=CELEX:32002L0058:en:HTML > Acesso em: 02.dez.2017

EUROPEAN PARLIAMENT AND COUNCIL. Directive 95/46/EC on the protection of individuals with regard to the processing of personal data and on the free movement of such data (Data protection directive). 24.out.1995. Disponível em: <http://eur-lex.europa.eu/legal-content/EN/TXT/?uri=CELEX:31995L0046> Acesso em: 02.dez.2017

EUROPEAN PARLIAMENT AND COUNCIL. Regulation 2016/679 on the protection of natural persons with regard to the processing of personal data and on the free movement of such data, and repealing Directive 95/46/EC (General Data Protection Regulation). 27.abr.2016. Disponível em: <http://eur-lex.europa.eu/legalcontent/EN/TXT/?uri=CELEX:32016R0679> Acesso em: 02.dez.2017

\subsection{WEBSITES}

COMISSÃO EUROPEIA. Página de Proteção de Dados Pessoais. Disponível em: <http://ec.europa.eu/justice/data-protection/index_en.htm>. Acesso em: 07.dez.2017.

FACEBOOK. Termos e Políticas do Facebook. Disponível em: <https://www.facebook.com/policies/>. Acesso em: 11.dez.2017. 
FACEBOOK. Cookies e outras tecnologias de armazenamento. Disponível em: <https://www.facebook.com/policies/cookies/>. Acesso em: 12.dez.2017.

FEDERAL TRADE COMMISSION. Do Not Track. Disponível em: $<$ https://www.ftc.gov/news-events/media-resources/protecting-consumerprivacy/do-not-track>. Acesso em: 03.dez.2017.

GOOGLE. Política e Termos. Disponível em: <https:// www.google.com.br/intl/pt-BR/policies/privacy/>. Acesso em: 28.nov.2017.

GOOGLE. Ajuda do Google Chrome. Limpar, ativar e gerenciar cookies no Chrome. Disponível em: <https://support.google.com/chrome/answer/95647>. Acesso em: 12.dez.2017.

PC WORLD. NHS Link to Facebook Raises Privacy Concerns. Disponível em: <http://www.pcworld.com/article/211711/article.html>. Acesso em: 27.nov.2017.

THE WALL STREET JOURNAL. On Orbitz, Mac Users Steered to Pricier Hotels. Disponível em: <http://www.wsj.com/articles/SB1000142405270230445 8604577488822667325882>. Acesso em: 02.dez.2017.

UOL ECONOMIA. Google e Facebook coletam mais dados que EUA, diz fundador do Wikileaks. Disponível em: <http://economia.uol.com.br/noticias /efe/2016/07/12/google-e-facebook-coletam-mais-dados-que-eua-diz-fundador-dowikileaks.htm>. Acesso em: 13.dez.2017. 